\title{
Amino acid substitutions in gyrA and parC associated with quinolone resistance in nalidixic acid-resistant Salmonella isolates
}

\author{
Dong Hwa Bae, Ho Jeong Baek, So Jeong Jeong and Young Ju Lee*
}

\begin{abstract}
This study was undertaken to identify and characterize amino acid substitutions in gyrA and parC related with quinolone resistance of 27 nalidixic acid-resistant $\left(\mathrm{Na}^{\mathrm{R}}\right)$ Salmonella isolates collected in poultry slaughterhouses in Korea. A total of 51 Salmonella isolates were detected from 44.8\% (47/105) of the total samples from 15 poultry slaughterhouses examined, among which $27(52.9 \%) \mathrm{Na}^{\mathrm{R}}$ isolates were detected while ciprofloxacin (Cip) resistance was not present in the isolates. These $27 \mathrm{Na}^{\mathrm{R}}$ isolates of DNA sequencing revealed that it contained three types of gyrA mutations in only D87 codon. Mutations in the D87 codon resulted in substitutions to $\mathrm{G}$ in most of the isolates, but D87Y and D87N exchanges were also detected. Although Cip resistance was absent, reduced susceptibility characterized by mutations in gyrA was apparent among Salmonella isolates from poultry slaughterhouses in Korea.
\end{abstract}

Keywords: gyrA, Nalidixic acid resistance, Salmonella

\section{Background}

Salmonellae are Gram-negative bacteria that are found worldwide in both cold- and warm-blooded animals as well as the environment. These bacteria are the main cause of salmonellosis in mammals and birds. Quinolone resistance in Salmonellae has developed over the last three decades since the introduction of $\mathrm{Na}$, the first synthetic lone antimicrobial agent [1]. Several mechanisms of quinolone resistance in Salmonella spp. have been documented including point mutations in the quinolone resistance-determining region (QRDR) of DNA gyrase ( $g y r A$ and $\operatorname{gyr} B$ ) or topoisomerase IV (parC and parE), expression of efflux pumps on the outer membrane, and plasmid-mediated quinolone resistance [1]. The goal of the present study was to identify and characterize gyrA and parC mutations associated with quinolone resistance in $27 \mathrm{Na}^{\mathrm{R}}$ Salmonella isolates collected from poultry slaughterhouses in South Korea.

\section{Methods}

A total of 51 Salmonella isolates were recovered from 105 samples (15 from the first and 15 from the last

\footnotetext{
* Correspondence: youngju@knu.ac.kr

College of Veterinary Medicine, Kyungpook National University, Daegu 702-701, Republic of Korea
}

chilling waters, and 75 from carcasses) collected at two out of nine duck slaughterhouses as well as 13 out of 41 chicken slaughterhouses located in different regions of South Korea. The first chilling water, the last chilling water, and five carcasses from each slaughterhouse were sampled. Bacteria were isolated from the samples according to the standard International Standardization Organization (ISO)-6579 method [2]. Serotyping was performed by slide and tube agglutination using $\mathrm{O}$ and $\mathrm{H}$ antiserum (Difco, USA) according to the Kauffmann and White scheme [3]. If two colonies showed the same serotypes and antimicrobial resistant patterns, only one colony was randomly chosen for analysis in this study.

Antimicrobial resistance of all 51 Salmonella isolates were evaluated using a disc diffusion test with the following discs (Difco): amikacin (An, $30 \mu \mathrm{g}$ ), ampicillin (Amp, $10 \mu \mathrm{g})$, chloramphenicol (C, $30 \mu \mathrm{g})$, ceftazidime (Caz, $30 \mu \mathrm{g})$, cephalothin (Cf, $30 \mu \mathrm{g})$, ciprofloxacin (Cip, $5 \mu \mathrm{g}$ ), cefotaxime (Ctx, $30 \mu \mathrm{g})$, cefazolin $(\mathrm{Cz}, 30 \mu \mathrm{g})$, cefepime (Fep, $30 \mu \mathrm{g}$ ), cefoxitin (Fox, $30 \mu \mathrm{g}$ ), gentamicin (Gm, $10 \mu \mathrm{g}$ ), imipenem (Imp, $10 \mu \mathrm{g})$, kanamycin (K, $30 \mu \mathrm{g})$, nalidixic acid $(\mathrm{Na}, 30 \mu \mathrm{g})$, norfloxacin (Nor, $10 \mu \mathrm{g})$, streptomycin (S, $10 \mu \mathrm{g})$, trimethoprim/sulfamethoxazole (Sxt, $1.25 / 23.75 \mu \mathrm{g})$, and tetracycline (Te, $30 \mu \mathrm{g})$. The results were evaluated according to the Clinical and Laboratory 
Standards Institute (CLSI) guidelines [4]. Escherichia coli ATCC 25922 was used as the control strain.

All 51 Salmonella isolates from the present study were further tested for amino acid changes in the QRDR, and screened for the presence of the $\operatorname{gyr} A$ and $\operatorname{parC}$ genes. Minimal inhibition concentrations (MICs) were determined for two antimicrobials, $\mathrm{Na}$ and $\mathrm{Cip}$, belonging to the quinolone and fluoroquinolone classes of antimicrobials, respectively, using an agar dilution method according to CLSI guidelines [4].

DNA was isolated for further molecular studies using a generation capture column kit (Qiagen, Germany) and stored at $-70^{\circ} \mathrm{C}$ before use. Fragments of the $\operatorname{gyrA}$ (F, 5'TGTCCGAGATGGCCTGAAGC-3'; R, 5'-TACCGTCATAGTTATCCACG-3') and parC (F, 5'-CTATGCG ATGTCAGAGCTGG-3'; R, 5'-TAACAGCAGCTCGG CGTATT-3') genes containing the QRDR associated with quinolone resistance were amplified by PCR and sequenced as previously described $[5,6]$. The PCR products were purified and sequenced by Macrogen Inc. (Daejeon, South Korea). The nucleotide sequences were analyzed with the Basic Local Alignment Search Tool (BLAST) on the National Center for Biotechnology Information (NCBI) website (http://blast.ncbi.nlm.nih.gov/Blast.cgi). DNA sequences of the $g y r A$ and $\operatorname{parC}$ genes were compared to those of native gyrA DNA (GenBank accession number X78977) and native parC DNA (GenBank accession number M68936), respectively.

\section{Results and discussion}

Resistance of the 51 Salmonella isolates to 18 antimicrobials is shown in Table 1. Resistance to at least one antimicrobial was found in $74.5 \%(\mathrm{n}=38)$ of the isolates while 12 isolates (23.5\%) showed multi-drug resistance to three or more classes of drug. Among the Salmonella isolates, resistance to $\mathrm{Na}(52.9 \%), \mathrm{S}(35.3 \%)$, and $\mathrm{Am}$ and Te $(21.6 \%)$ was frequently observed. None of the isolates were resistant to An, Cip, Fox, Imp, Nor, or Sxt. Seven out of eight $S$. Typhimurium isolates remained susceptible to all the tested antimicrobials. $S$. Enteritis and $S$. Hadar isolates showed the highest rates of antimicrobial resistance in this study. Nine out of $18 \mathrm{~S}$. Enteritidis isolates were resistant to at least three antimicrobial agents while the remaining nine isolates were resistant to one antimicrobial compound. All five $S$. Hadar isolates were resistant to more than two antimicrobial agents. A previous report determined that $S$. Hadar is one of the most resistant Salmonella serotypes [7].

In the present study, Na resistance (52.9\%) was predominant among the 51 Salmonella isolates. Twenty-seven $\mathrm{Na}^{\mathrm{R}}$ isolates were serotyped as $S$. Enteritidis $(\mathrm{n}=18), S$. Montevideo $(\mathrm{n}=5), S$. Senftenberg $(\mathrm{n}=2)$, and $S$. Newport

Table 1 Prevalence of antimicrobial resistance in 51 Salmonella isolates from poultry slaughterhouses

\begin{tabular}{|c|c|c|c|c|c|c|c|c|c|c|}
\hline \multirow[t]{2}{*}{ Antimicrobials * } & \multicolumn{9}{|c|}{ No (\%). of serovars } & \multirow{2}{*}{$\begin{array}{l}\text { Total } \\
(\mathrm{n}=51)\end{array}$} \\
\hline & $\begin{array}{l}\text { Enteritidis } \\
\qquad(n=18)\end{array}$ & $\begin{array}{c}\text { Montevideo } \\
(n=9)\end{array}$ & $\begin{array}{l}\text { Typhimurium } \\
(n=8)\end{array}$ & $\begin{array}{l}\text { Hadar } \\
(n=5)\end{array}$ & $\begin{array}{l}\text { London } \\
(\mathrm{n}=3)\end{array}$ & $\begin{array}{l}\text { Ohio } \\
(n=3)\end{array}$ & $\begin{array}{l}\text { Newport } \\
(n=2)\end{array}$ & $\begin{array}{l}\text { Senftenberg } \\
\qquad(n=2)\end{array}$ & $\begin{array}{c}\text { Hogton } \\
(n=1)\end{array}$ & \\
\hline $\mathrm{Na}$ & $18(100)$ & $5(55.6)$ & - & - & - & - & $2(100)$ & $2(100)$ & - & $27(52.9)$ \\
\hline S & $9(50.0)$ & - & $1(12.5)$ & $5(100)$ & $1(33.3)$ & $1(33.3)$ & - & - & $1(100)$ & $18(35.3)$ \\
\hline $\mathrm{Am}$ & $8(44.4)$ & - & - & $2(40.0)$ & $1(33.3)$ & - & - & - & - & $11(21.6)$ \\
\hline $\mathrm{Te}$ & $3(16.7)$ & - & $1(12.5)$ & $4(80.0)$ & $1(33.3)$ & $1(33.3)$ & - & - & $1(100)$ & $11(21.6)$ \\
\hline Cf & $3(16.7)$ & - & - & $2(40.0)$ & $1(33.3)$ & - & - & - & - & $6(11.8)$ \\
\hline K & $1(5.6)$ & $2(22.2)$ & - & $2(40.0)$ & - & - & - & - & $1(100)$ & $6(11.8)$ \\
\hline $\mathrm{Cz}$ & $1(5.6)$ & - & - & $2(40.0)$ & - & - & - & - & - & $3(5.9)$ \\
\hline $\mathrm{Gm}$ & $1(5.6)$ & $2(22.2)$ & - & - & - & - & - & - & - & $3(5.9)$ \\
\hline C & $1(5.6)$ & - & - & - & - & - & - & - & - & $1(2.0)$ \\
\hline Caz & $1(5.6)$ & - & - & - & - & - & - & - & - & $1(2.0)$ \\
\hline Ctx & $1(5.6)$ & - & - & - & - & - & - & - & - & $1(2.0)$ \\
\hline Fep & $1(5.6)$ & - & - & - & - & - & - & - & - & $1(2.0)$ \\
\hline$A n$ & - & - & - & - & - & - & - & - & - & $0(0.0)$ \\
\hline Cip & - & - & - & - & - & - & - & - & - & $0(0.0)$ \\
\hline Fox & - & - & - & - & - & - & - & - & - & $0(0.0)$ \\
\hline Imp & - & - & - & - & - & - & - & - & - & $0(0.0)$ \\
\hline Nor & - & - & - & - & - & - & - & - & - & $0(0.0)$ \\
\hline Sxt & - & - & - & - & - & - & - & - & - & $0(0.0)$ \\
\hline
\end{tabular}

${ }^{*}$ An, amikacin; Am, ampicillin; C, chloramphenicol; Caz, ceftazidime; Cf, cephalothin; Cip, Ciprofloxacin; Ctx, cefotaxime; Cz, cefazolin; Fep, cefepime; Fox, cefoxitin; Gm, gentamicin; Imp, imipenem; K, kanamycin; Na, nalidixic acid; Nor, norfloxacin; S, streptomycin; Sxt, trimethoprim/sulfamethoxazole; Te, tetracycline. 
$(\mathrm{n}=2)$. Na resistance does not seem to have decreased during the last several years in South Korea and rates of resistance remain higher compared to those reported in other countries. $\mathrm{Na}$ resistance rates among Salmonella strains originating from chickens were found to range from $37 \%$ to $94.3 \%$ over the last 6 years [8-12]. In contrast, Salmonella isolates from poultry meats from several sources in Canada were shown to lack Na resistance [13] while very low levels of resistance were observed among isolates from Japan (10.9\%) [14] and the UK (28.2\%) [15].

MICs for $\mathrm{Na}$ and Cip are presented in Table 2. Among the 51 isolates, $27(52.9 \%)$ were $\mathrm{Na}^{\mathrm{R}}(\mathrm{MIC} \geq 512 \mu \mathrm{g} / \mathrm{mL})$ while the remaining $24(47.1 \%)$ were susceptible to $\mathrm{Na}$ $(\mathrm{MIC}=4-16 \mu \mathrm{g} / \mathrm{mL})$. Interestingly, all 51 isolates were susceptible to Cip (MIC $\leq 0.5 \mu \mathrm{g} / \mathrm{mL}$ ). In addition, all $18 \mathrm{~S}$. Enteritidis isolates collected in the present study were highly resistant to $\mathrm{Na}(\mathrm{MIC} \geq 512 \mu \mathrm{g} / \mathrm{mL})$ while all eight $S$. Typhimurium isolates were susceptible $(\mathrm{MIC}=$ $8-16 \mu \mathrm{g} / \mathrm{mL})$.

Table 2 shows amino acid substitutions in gyrA and parC found in the $27 \mathrm{Na}^{\mathrm{R}}$ isolates. These results indicate that mutations only at position 87 in gyrA conferred both $\mathrm{Na}$ resistance and Cip susceptibility. All $27 \mathrm{Na}^{\mathrm{R}}$ isolates possessed three different types of point mutations only at position 87 in gyrA and carried a D87 to G, $\mathrm{Y}$, or $\mathrm{N}$ substitution. Among these $27 \mathrm{Na}^{\mathrm{R}}$ isolates, the most common gyrA mutation was D87G (51.9\%) followed by D87Y (37.0\%) and D87N (11.1\%). No mutations at S83 of gyrA were observed in any isolate from the present study. No mutation in parC that affected resistance or susceptibility was identified. However, silent mutations at V67, H75, H77, V100, D101, and G102 were found within the QRDR of parC.

Our data may confirm that the mutations at S87 of gyrA alone can be sufficient to induce $\mathrm{Na}$ resistance and Cip susceptibility. Additionally, results from the present study imply that parC mutations are not necessary to obtain a high level of $\mathrm{Na}$ resistance as hypothesized in previous reports $[16,17]$.

Our findings contrast with those generated by Griggs et al. [6] and Liebana et al. [18] showing that 95.4\% and $50 \%$ of Salmonella isolates from animals contained a

Table 2 Amino acid substitutions in gyrA and parC and antimicrobial resistance profiles in 51 Salmonella isolates from poultry slaughterhouses by nalidixic acid resistance

\begin{tabular}{|c|c|c|c|c|c|c|}
\hline \multirow{2}{*}{$\begin{array}{c}\text { Resistance } \\
\text { pattern of } \\
\text { nalidixic acid }\end{array}$} & \multirow{2}{*}{$\begin{array}{c}\text { Serovars } \\
\text { (No. of isolates ) }\end{array}$} & \multicolumn{2}{|c|}{ Amino acid substitution in ${ }^{*}$} & \multicolumn{2}{|c|}{$\mathrm{MICs}^{\ddagger}(\mathrm{mg} / \mathrm{l})$} & \multirow[t]{2}{*}{ Antimicrobial resistance profiles } \\
\hline & & GyrA & ParC & $\mathrm{Na}$ & Cip & \\
\hline \multirow[t]{10}{*}{ Resistant } & Enteritis (18) & D87G & $\mathrm{WT}^{\dagger}$ & 512 & 0.25 & AmCSTe (1), Ams (2), STe (1) \\
\hline & & & & 512 & 0.5 & AmCfS (2), Ams (2) \\
\hline & & D87Y & WT & $>512$ & 0.5 & $-(8)$ \\
\hline & & $\mathrm{D} 87 \mathrm{~N}$ & WT & $>512$ & 0.5 & AmCfCzGmKCazCtxFepSTe (1), - (1) \\
\hline & Montevideo (5) & D87G & WT & $>512$ & 0.25 & $-(2)$ \\
\hline & & & & 512 & 0.25 & $-(3)$ \\
\hline & Senftenberg (2) & $\mathrm{D} 87 \mathrm{~N}$ & WT & 512 & 0.5 & $-(1)$ \\
\hline & & D87G & WT & 512 & 0.25 & $-(1)$ \\
\hline & Newport (2) & D87Y & WT & 512 & 0.5 & $-(1)$ \\
\hline & & & & $>512$ & 0.5 & $-(1)$ \\
\hline \multirow[t]{10}{*}{ Susceptible } & Typhimurium (8) & WT & WT & 8 & $<0.0625$ & $-(6)$ \\
\hline & & & & 8 & 0.25 & $-(1)$ \\
\hline & & & & 16 & $<0.0625$ & STe (1) \\
\hline & Montevideo (4) & WT & WT & 4 & $<0.0625$ & $\operatorname{GmK}(2),-(2)$ \\
\hline & Hadar (5) & WT & WT & 4 & $<0.0625$ & AmCfCzSTe (1) \\
\hline & & & & 8 & $<0.0625$ & AmCfCzKSTe (1), STe (2), KS (1) \\
\hline & Ohio (3) & WT & WT & 4 & $<0.0625$ & $\operatorname{STe}(1),-(2)$ \\
\hline & London (3) & WT & WT & 4 & $<0.0625$ & AmCfSTe (1) \\
\hline & & & & 8 & $<0.0625$ & $-(2)$ \\
\hline & Hogton (1) & WT & WT & 8 & $<0.0625$ & KSTe (1) \\
\hline
\end{tabular}

${ }^{*} D$, aspartic acid; $G$, glycine; $N$, asparagine; $Y$, tyrosine.

${ }^{\dagger} \mathrm{WT}$, wild type.

‡ Cip, ciprofloxacin; $\mathrm{Na}$, nalidixic acid.

${ }^{\S} \mathrm{Am}$, ampicillin; C, chloramphenicol; Caz, ceftazidime; Cf, cephalothin; Cz, cefazolin; Ctx, cefotaxime; Fep, cefepime; Gm, gentamicin; K, kanamycin; S, streptomycin; Te, tetracycline. 
S83 mutation. Mutations at S83 of gyrA have been described in Salmonella isolates from humans and animals [6], and are thought to promote resistance to $\mathrm{Na}$ while reducing fluoroquinolone susceptibility.

Piddock [19] also reported that the number of quinoloneresistant Salmonella spp. encountered in human and veterinary medicine is increasing. Other previous investigations [20-22] demonstrated that a single mutation in the gyrA gene is associated with Cip susceptibility. In contrast, parC mutations can result in a high level of fluoroquinolone resistance [21].

\section{Conclusion}

In conclusion, results from the present study showed that mutations in codon D87 of the gyrA gene are sufficient for conferring Na resistance and Cip susceptibility. Our findings also suggest that mutations in codon S83 of the $g y r A$ gene are not a main factor of Na resistance, and $\operatorname{par} C$ mutations are not essential for quinolone resistance. Therefore, prudent use of antimicrobials and continued surveillance are absolutely needed to inhibit the increasing prevalence of quinolone resistance.

\section{Abbreviations}

QRDR: Quinolone resistance-determining region; ISO: International standardization organization; CLSI: Clinical and laboratory standards institute; MICs: Minimal inhibition concentrations; BLAST: Basic local alignment search tool; NCBI: National center for siotechnology information.

\section{Competing interests}

The authors declare that they have no competing interests.

\section{Authors' contributions}

DHB analyzed the samples, performed the statistical analysis and wrote the manuscript. HJB and SJJ helped collect and analyse the samples. YJL provided the basic format of the study, obtained the funding and acted as study team leader. All authors read and approved the final manuscript.

Received: 8 October 2013 Accepted: 14 November 2013

Published: 15 November 2013

\section{References}

1. Năşcuțiu AM: The tip of the iceberg: quinolone-resistance conferred by mutations in gyrA gene in non-typhoidal Salmonella strains. Roum Arch Microbiol Immunol 2012, 71:17-23.

2. ISO 6579: Microbiology of food and animal feeding stuff-horizontal method for the detection of Salmonella. 4th edition. Geneva: Swiss; 2002

3. Popoff MY, Le Minor L: Antigenic formulas of the salmonella serovars, 7th revision. World Health Organization collaborating centre for reference and research on Salmonella. Paris, France: Pasteur Institute; 1997.

4. CLSI: Performance standards for antimicrobial susceptibility testing, 17th informational supplement M100-S17. USA: Wayne, PA 19087; 2007.

5. Eaves DJ, Liebana E, Woodward MJ, Piddock LJ: Detection of gyrA mutations in quinolone-resistant Salmonella enterica by denaturing high-performance liquid chromatography. J Clin Microbio/ 2002, 40:4121-4125.

6. Griggs DJ, Gensberg K, Piddock LJ: Mutations in gyrA gene of quinoloneresistant Salmonella serotypes isolated from humans and animals. Antimicrob Agents Chemother 1996, 40:1009-1013.

7. Wybot I, Wildemauwe C, Godard C, Bertrand S, Collard JM: Antimicrobial drug resistance in nontyphoid human Salmonella in Belgium: trends for the period 2000-2002. Acta Clin Belg 2004, 59:152-160.

8. Cheong HJ, Lee YJ, Hwang IS, Kee SY, Cheong HW, Song JY, Kim JM, Park $\mathrm{YH}$, Jung JH, Kim WJ: Characteristics of non-typhoidal Salmonella isolates from human and broiler-chickens in southwestern Seoul, Korea. J Korean Med Sci 2007, 22:773-778.

9. Kang MS, Kim A, Jung BY, Her M, Jeong W, Cho YM, Oh JY, Lee YJ, Kwon JH, Kwon YK: Characterization of antimicrobial resistance of recent Salmonella enterica serovar Gallinarum isolates from chickens in South Korea. Avian Pathol 2010, 39:201-205.

10. Kang ZW, Jung JH, Kim SH, Lee BK, Lee DY, Kim YJ, Lee JY, Won HK, Kim EH, Hahn TW: Genotypic and phenotypic diversity of Salmonella enteritidis isolated from chickens and humans in Korea. J Vet Med Sci 2009, 71:1433-1438.

11. Kim MS, Lim TH, Jang JH, Lee DH, Kim BY, Kwon JH, Choi SW, Noh JY, Hong YH, Lee SB, Yang SY, Lee HJ, Lee JB, Park SY, Choi IS, Song CS: Prevalence and antimicrobial resistance of Salmonella species isolated from chicken meats produced by different integrated broiler operations in Korea. Poult Sci 2012, 91:2370-2375.

12. Lee $K$, Lee M, Lim J, Jung J, Park Y, Lee Y: Contamination of chicken meat with Salmonella enterica Serovar Haardt with nalidixic acid resistance and reduced fluoroquinolone susceptibility. J Microbiol Biotechnol 2008, 18:1853-1857.

13. Aslam M, Checkley S, Avery B, Chalmers G, Bohaychuk V, Gensler G, Reid-Smith $R$, Boerlin P: Phenotypic and genetic characterization of antimicrobial resistance in Salmonella serovars isolated from retail meats in Alberta, Canada. Food Microbiol 2012, 32:110-117.

14. Sasaki Y, Ikeda A, Ishikawa K, Murakami M, Kusukawa M, Asai T, Yamada Y: Prevalence and antimicrobial susceptibility of Salmonella in Japanese broiler flocks. Epidemiol Infect 2012, 140:2074-2081.

15. Little CL, Richardson JF, Owen RJ, de Pinna E, Threlfall EJ: Prevalence, characterisation and antimicrobial resistance of Campylobacter and Salmonella in raw poultrymeat in the UK, 2003-2005. Int J Environ Health Res 2008, 18:403-414.

16. Reche MP, Ríos JE G d I, Jiménez PA, Rojas AM, Rotger R: gyrA Mutations associated with nalidixic acid-resistant Salmonellae from wild birds. Antimicrob Agents Chemother 2002, 46:3108-3109.

17. Ruiz J, Castro D, Goñi P, Santamaria JA, Borrego JJ, Vila J: Analysis of the mechanism of quinolone resistance in nalidixic acid-resistant clinical isolates of Salmonella serotype Typhimurium. J Med Microbiol 1997, 46:623-628.

18. Liebana E, Clouting C, Cassar CA, Randall LP, Walker RA, Threlfall EJ, Clifton-Hadley FA, Ridley AM, Davies RH: Comparison of gyrA mutations, cyclohexane resistance, and the presence of class I integrons in Salmonella enterica from farm animals in England and Wales. J Clin Microbio/ 2002, 40:1481-1486.

19. Piddock $\sqcup$ : Fluoroquinolone resistance in Salmonella serovars isolated from humans and food animals. FEMS Microbiol Rev 2002, 26:3-16.

20. Acharya D, Trakulsomboon S, Madhup SK, Korbsrisate S: Antibiotic susceptibility pattern and the indicator of decreased ciprofloxacin susceptibility of Salmonella enterica serovar Typhi isolated from Dhulikhel Hospital, Nepal. Jpn J Infect Dis 2012, 65:264-267.

21. Dimitrov T, Dashti AA, Albaksami O, Udo EE, Jadaon MM, Albert MJ: Ciprofloxacin-resistant Salmonella enterica serovar Typhi from Kuwait with novel mutations in gyrA and parC genes. J Clin Microbiol 2009, 47:208-211.

22. Hirose K, Hashimoto A, Tamura K, Kawamura Y, Ezaki T, Sagara H, Watanabe $\mathrm{H}$ : DNA sequence analysis of DNA gyrase and DNA topoisomerase IV quinolone resistance-determining regions of Salmonella enterica serovar Typhi and serovar Paratyphi A. Antimicrob Agents Chemother 2002 46:3249-3252

doi:10.1186/2046-0481-66-23

Cite this article as: Bae et al:: Amino acid substitutions in gyrA and parC associated with quinolone resistance in nalidixic acid-resistant Salmonella isolates. Irish Veterinary Journal 2013 66:23. 